\title{
Apuntes para una teoría de la poesía infantil
}

\author{
Notes for a Theory of the Infant Poetry
}

\author{
Ramón Luis Herrera Rojas \\ Universidad de Sancti Spíritus «José Martí» \\ rluis@uniss.edu.cu \\ ORCID iD: http://orcid.org/0000-0002-2483-7193
}

\section{RESUMEN}

Se caracterizan los rasgos considerados esenciales de la poesía infantil, a la luz de una visión integradora e interdisciplinar que toma en cuenta las ciencias del lenguaje y de la literatura contemporáneas. La vuelta del lenguaje hacia sí mismo en una materialidad fónico-rítmica de los significantes estimuladora de acciones lúdicas; la intertextualidad con el caudal folclórico oral; la densidad isotópica favorecedora de la coherencia textual; la narratividad dinamizadora del discurso; el predominio de lo imaginal sobre lo abstracto; la constitución frecuente de hablantes líricos infantiles, son, entre otros, factores que tienden a estimular la recepción y que caracterizan a un género literario proclive a una relación singular con la tradición y que se mueve entre tensiones resueltas ejemplarmente en la obra de muchos poetas de alta maestría creadora. Se ejemplifican dichos rasgos mediante textos de algunos de los más relevantes autores de España e Hispanoamérica.

Palabras Clave: poesía infantil; literatura infantil y juvenil; materialidad fónico-rítmica; Lector Modelo; isotopía; intertextualidad; sujeto lírico.

\section{ABSTRACT}

The essential features of infant poetry, under an integrating and interdisciplinary vision, taking into account Language and Literature contemporary sciences are presented in this work. Language turns on itself in a phonic-rhythmic materializing of stimulating meanings of ludic actions; interculturality with oral traditional flow; the isotopic density favoring text coherence; speech dynamiting narration; the prevailing of imaginary remarkable sense over abstract; the visual constitution of lyric infantile speakers are, among other, factors tending to a singular relation with tradition and moving among exceptionally solved tensions in the work of many highly creative poets. Such aspects are exemplified by means of some texts, by relevant Spanish and Latin American authors.

Key words: Infant Poetry; Youth and Infant Literature; Phonic-rhythmic Materializing; Model Readers; Isotopic; Intertextuality; Lyric Subject. 
Los estudios acerca de la poesía infantil son más bien escasos. Si la literatura para niños y jóvenes toda fue casi ignorada por la academia hasta bien entrado el siglo XX —-salvo manifestaciones genéricas que, como el cuento maravilloso, eran investigadas por folcloristas, etnógrafos, antropólogos, historiadores literarios, de lo cual resulta paradigmático el libro Morfología del cuento (1928), de Vladímir Propp (1895-1970) — la poesía dedicada a la infancia, que está en los márgenes de lo ya de por sí marginal, fue sencillamente dejada de lado o tratada en función de la pedagogía, cuando no a la luz de un impresionismo crítico ajeno a las elaboraciones teórico-metodológicas de la estilística, la poética, la versología, la semiótica, el estructuralismo o la nueva retórica.

Esta situación, sin embargo, ha cambiado para bien en las últimas décadas. Marc Soriano dedicó a la poesía una entrada de su monumental La literatura para niños y jóvenes. Guía de exploración de sus grandes temas, de 1994, y ya en el ámbito de la lengua española, han aparecido textos valiosos como los de Luis García Montero (1989), Benjamín Prado (2000), Cecilia Bajour ${ }^{1}$, Pedro C. Cerrillo y Ángel L. Luján (2010). Un pionero de este quehacer que le concede a la poesía infantil un estatuto similar al de la narrativa mediante la incorporación de los aportes de las ciencias o teorías contemporáneas de la literatura es el libro Introducción a la literatura infantil (1985 y 1990), del español Román López Tamés, que en su capítulo «La poesía infantil», profundiza en las claves semánticas y estructurales de este género con aguda visión interdisciplinar.

La poesía infantil, entendida como aquella producción lírica escrita de modo premeditado por un adulto para los niños o convertida en parte del repertorio de lecturas de aquellos por diferentes causas - es decir, hecha suya por receptores que corresponden a las edades preescolar y escolar primaria, hasta los umbrales de la adolescencia - es un caso típico de textualidad polarizada pragmáticamente hacia un receptor específico. Ello la asemeja hasta cierto punto con variantes genéricas como la novela rosa, policial o del Oeste, concebidas ex profeso para estratos específicos del público lector.

Solo hasta cierto punto, porque escribir y publicar para un sector acotado previamente sobre la base de un perfil sociocultural determinante del consumo, dista mucho de hacerlo para una entidad abstracta como la infancia, que en su universalismo sustentado en una periodización de la vida humana, engloba un sinfín de rasgos diferenciales de orden clasista, histórico, cultural en suma, durante una etapa de la existencia en que el proceso de ontogénesis establece

${ }^{1}$ Bajour, Cecilia (2013). «Nadar en aguas inquietas: una aproximación a la poesía infantil de hoy», Imaginaria. 332. Disponible en: <http://www.imaginaria.com.ar/2013/09/ nadar-en-aguas-inquietas-una-aproximacion-a-la-poesia-infantil-de-hoy/> [ref. de 21/6/2017] 
una dinámica muy particular en la evolución de la psiquis, con todo lo que ello implica.

Pese a su aparente simplicidad, la poesía infantil es fuente de complejos problemas para la investigación literaria: ¿por qué son tan frecuentes las tensiones entre comunicación y literariedad?, ¿por qué parece detenida en el tiempo, como si le fueran ajenos los bruscos cambios que transformaron enormemente la poesía desde los tiempos de la Vanguardia en las primeras décadas del siglo XX?, ¿por qué es tan fiel a pautas métricas y retóricas, continuadoras de la tradición, no solo en español, sino también en otros ámbitos lingüísticos?, ¿por qué la naturaleza del sujeto o hablante lírico es tan particular en los poemas destinados a la infancia?, ¿es posible una caracterización de la poesía infantil en tanto discurso de constantes semánticas, estructurales, estilísticas, reconocibles?

Intentar respuestas mínimamente coherentes a esas y otras preguntas que aparecerán por el camino, nutridas de los aportes de los estudios literarios y de otras ciencias afines (lingüística, semiótica, teoría de la comunicación...) de los últimos cien años, es el propósito de estas notas que por encima de todo parten de una convicción: la poesía para niños es tan digna de investigación como su similar genérica para los adultos, porque ella es una muy legítima expresión de la literatura, prestigiada por excelentes poetas y subestimarla es un inculto prejuicio. Las presentes reflexiones se unen, por tanto, a un creciente universo de estudios, indicativos de la trascendencia de la poesía para niños y de la literatura infantil y juvenil (en adelante LIJ) toda como expresión cultural cada vez más merecedora de reflexión teórica, de lo cual son ejemplos los libros y artículos antes mencionados y otros de considerable difusión internacional como los de Zohar Shavit (2009), Seth Lerer (2009), Margaret Meek (2001) o Angelo Nobile (1992).

II

La poesía infantil es quizás el caso extremo de opacidad del lenguaje, del lenguaje vuelto hacia sí mismo de que habló Roman Jakobson en su célebre conferencia «La lingüística y la poética» (1974: 123-173) como elemento definitorio de la función poética.

La muy ostensible materialidad fónico-rítmica que establece dicha opacidad, es quizás el rasgo más acusado de la poesía infantil. Tan marcado, que convierte en intraducibles formas genéricas, de la tradición oral popular o muy cercanas a ella como las nursery rhymes inglesas, las comptines francesas, las filastrocche italianas y los trabalenguas del ancho ámbito del español, por solo citar ejemplos muy conocidos.

En estas manifestaciones literarias la función lúdica pasa al primer plano, en una intensificación de la naturaleza de juego inherente a todo lo poético, 
pero con importantes resonancias identitarias, en el sentido de la pertenencia a una nación o a una comunidad lingüística, tal como explica Paul Hazard, por ejemplo, a propósito de las nursery rhymes (1989: 114-122).

Esa tematización del juego en el texto, comunicada esencialmente por las combinaciones fónicas iterativas («En Cacarajícara hay una jícara...», «Era una cabra ética, pelética, pelada, peluda...») suele aparecer junto a expresiones de aparente sinsentido (o con el puro juego como sentido principal) que sitúan estos textos tan gustados en el extremo opuesto de lo didáctico y lo moralizante.

Muchas de estas composiciones forman parte del folclor, pero otras tantas pertenecen a la invención de autores de la tradición letrada que hallan en ese juego con el idioma un filón creativo al parecer inagotable, lo que se aprecia en poetas tan conocidos como Maurice Carême (1899-1978), Gianni Rodari (1920-1980) o Gloria Fuertes (1917-1998). Pero incluso, en poemas de asunto patriótico o de pura recreación lírica esa aludida materialidad fónico-rítmica sigue siendo protagónica, sobre todo en términos de métrica y de otras recurrencias sonoras de diversa índole, hecho totalmente apartado de la corriente principal de la poesía contemporánea.

Al respecto pudieran aventurarse algunas hipótesis que tratan de explicar algo que en muchos escritos sobre LIJ es, sin más, una simple constatación o un deber ser perentorio.

Ese protagonismo de los significantes, que como se dijo antes, en algunos casos como los del trabalenguas, por sí mismos llegan a ser significados, parece deberse a:

- El peso de las convenciones literarias institucionalizadas,

- la influencia de la oralidad folclórica,

- la necesidad de la densidad o saturación de isotopías para lograr la atención, la comprensión y el disfrute del receptor, que es oyente o lector en tránsito de conformar su competencia literaria.

Respecto del concepto de isotopía, muy funcional en el contexto de la presente exposición, se sigue la denominación de A. J. Greimas en Du sens. Essais sémiotiques:

[...] por isotopía entendemos un conjunto redundante de categorías semánticas que hacen posible la lectura uniforme del relato, tal como resulta de lecturas parciales de los enunciados y de la resolución de sus ambigüedades, que es guiada por la búsqueda de la lectura única $(1970: 188)^{2}$.

Como suele ocurrir en el universo de la subjetividad humana, los factores interactuantes son múltiples, aunque sea posible distinguir el de importancia

\footnotetext{
2 Traducción del autor.
} 
decisiva. De las tres hipótesis anteriores, las dos primeras son contribuyentes y la última fundamental, pues ella da cuenta de la probada coincidencia entre los rasgos definitorios de la literatura oral y la naturaleza del receptor infantil.

Por convenciones institucionales se entenderá aquí, en la estela de las concepciones del teórico belga Jacques Dubois (1988: 31-24), aquellas prácticas de escritura legitimadas por las instancias del reconocimiento y la consagración que se han revelado exitosas y que se siguen aun con olvido, incluso con frecuente olvido, de la espiritualidad personal.

Esas convenciones a menudo tan ajenas a la individualización creadora abarcan las elecciones temáticas y los rasgos de estilo y parecen explicar en cierta medida la persistencia de fenómenos como el apabullante zoologismo o la saturación muy visible en mucha poesía infantil de Latinoamérica, por ejemplo, de juegos verbales emparentados con la jitanjáfora ${ }^{3}$.

De modo que desde la influencia de ese factor, la mencionada materialidad fónico-rítmica se cultiva siguiendo una suerte de inercia consistente en continuar con lo ya probado y además premiado, publicado y aprendido quizás desde los primeros libros escolares. No obstante, este factor está lejos de ser el determinante, como se verá a continuación.

La influencia de la oralidad folclórica se deja sentir en todo el espectro genérico de la LIJ, como ha explicado agudamente el sabio francés Marc Soriano en La literatura para niños y jóvenes. Guía de exploración de sus grandes temas (2005). Tras milenios de intenso contacto de la infancia con ese caudal de prodigiosa inventiva, es de suponer que en el gradual proceso de consolidación de la edición y la escritura en la modernidad capitalista con rezagos de feudalismo, a partir del siglo XVII, destinada a niños y jóvenes, la huella de esa poderosa oralidad sea muy notable tanto en el ámbito de las primigenias ediciones (recuérdense las de John Newbery, a mediados del siglo XVIII en Gran Bretaña), como en los autores, desde Charles Perrault (16281703) en la narrativa, hasta Edward Lear (1812-1888) en la poesía.

Aun habiendo vivido el extraordinario florecimiento de la LIJ en el siglo XIX, tan ligado al auge de la escolarización europea y norteamericana; a la maduración del dispositivo editorial; al impulso del romanticismo a la libre imaginación y del realismo al buceo en conflictos contemporáneos; al ascenso de los nacionalismos y, por supuesto, a la creatividad de una constelación de talentos de primer orden; aun con el no menos portentoso cuerpo textual del siglo XX, tan pródigo en búsquedas insólitas y hallazgos afortunados, ese influjo de lo folclórico mantiene una tenaz vigencia.

\footnotetext{
${ }_{3}$ Palabra que aparece en un poema del poeta cubano Mariano Brull (1891-1956), que posteriormente se utiliza para designar un texto lírico caracterizado por el empleo de vocablos inventados de llamativa sonoridad y clara intención lúdica. Fue puesta en circulación por Alfonso Reyes (1889-1959), quien contó en un muy interesante texto los hechos que rodearon el surgimiento de tal término.
} 
Así la llamativa permanencia de la tradición métrica puede ser asociada no solo al prestigio de las convenciones consagradas, sino también a la influencia perdurable de la oralidad folclórica, que se expresa en formas estróficas como el pareado, la cuarteta, la redondilla y el romance, con amplio predominio de la medida del octosílabo.

Un poema de José Martí, incluido en el segundo número de su revista $L a$ Edad de Oro (1889), desde inicios del siglo XX publicado en forma de libro, ilustra de modo meridiano varias de las ideas anteriores. El texto, considerado de alto valor por la crítica (Florit, 1989; Portuondo, 1989; Chacón y Calvo, 1989; Marinello, 1989; entre otros) se inscribe precisamente en la tradición popular española del romance con singular maestría estilística, a la vez que transgrede en tan alta medida los tópicos de la literatura infantil, que aún resulta incómodo para quienes inscriben la poesía para niños en una inocua retórica de la ternura o en un regodeo lúdico olvidadizo de las angustias del ser humano:

\section{Los dos príncipes}

Idea de la poetisa norteamericana Helen Hunt Jackson

El palacio está de luto

$\mathrm{Y}$ en el trono llora el rey,

Y la reina está llorando

Donde no la puedan ver:

En pañuelos de holán fino

Lloran la reina y el rey:

Los señores de palacio

Están llorando también.

Los caballos llevan negro

El penacho y el arnés:

Los caballos no han comido,

Porque no quieren comer:

El laurel del patio grande

Quedó sin hoja esta vez:

Todo el mundo fue al entierro

Con coronas de laurel:

— iEl hijo del rey se ha muerto!

¡Se le ha muerto el hijo al rey!

En los álamos del monte

Tiene su casa el pastor:

La pastora está diciendo

«¿Por qué tiene luz el sol?»

Las ovejas, cabizbajas,

Vienen todas al portón:

¡Una caja larga y honda

Está forrando el pastor!

Entra y sale un perro triste: 


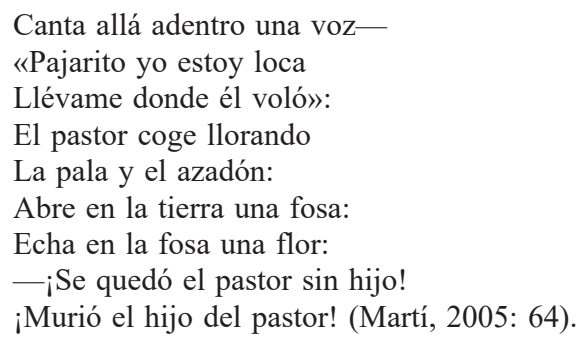

III

Por otro lado, resulta muy visible la intertextualidad (en la acepción más restringida de la clasificación de Gérard Genette ${ }^{4}$ ) de numerosos poemas con referentes folclóricos, visible en el anterior romance martiano tanto con el texto declarado por el propio autor («The prince is dead»), como con el formidable caudal del romancero hispánico, pero con una desgarrada intensidad emotiva heredera del más auténtico romanticismo y expresiva de la personalísima estética del bardo cubano. En esta manifestación de lo intertextual los ecos entre los nuevos textos y aquellos de la oralidad conducen a la desautomatización de las fórmulas verbales, con variable fortuna estética. Nótese la ingeniosa y humorística recreación de Dora Alonso (1910-2001) de la cuarteta irregular empleada en la selección de participantes en los juegos de los niños de Cuba: Tin Marín / de dos pingüé, / cúcara mácara / títere fue:

\section{Nadie sabe}

El payaso de algún circo

Tin Marín pudiera ser; pero la cúcara mácara nadie sabe lo que es (1989: 80).

O la también muy lograda «Canción vieja», de José Manuel Espino (1966), que retoma una copla conocida en todo el ámbito de la lengua española y la mezcla con graciosas referencias architextuales a los cuentos maravillosos:

\footnotetext{
Para volar bien alto

se necesita

polvo de un hada grande

y otra chiquita.

Si es polvo de hada grande

me da calambre,
}

\footnotetext{
4 Véase Desiderio Navarro (1997: 53-62), donde se incluye la traducción de partes de Palimpsestes: la littérature au second degré (1982), de Genette.
} 
si es polvo de hada chiquita

me da salsita (2003: 64).

Las citas y reflexiones anteriores vinculan la segunda con la tercera hipótesis: las relaciones intertextuales con el legado folclórico en la poesía y en los restantes géneros de la LIJ se sustentan en la certeza de que se comparte con el receptor infantil o adolescente una memoria común de intensa afectividad, ligada a algo tan trascendente para él como el juego. Este campo de interacción entre la literatura tradicional y el receptor infantil cuenta con numerosos estudios, desde diversos ángulos, que van desde la exploración en el folclor hasta la teoría de la recepción, pasando por el psicoanálisis y la didáctica de la lengua y la literatura. Un libro revelador del estado actual de tales acercamientos a dicho campo lo constituye Tradición y modernidad de la literatura oral (2010), coordinado por los investigadores españoles Pedro C. Cerrillo Torremocha y César Sánchez Ortiz.

La presuposición de un ideal de receptor (Archilector según Michael Riffaterre [1971: 46], Lector modelo según Umberto Eco [1985: 61]); de una suerte de lector niño ideal cuya recepción es posible pilotear desde el texto, está en la base de la tercera hipótesis.

Por tanto, la enunciada densidad o saturación isotópica se halla esencialmente determinada por la naturaleza del receptor niño y uno de los factores que más contribuyen a esa muy marcada redundancia, a esa hipercoherencia textual, es la materialidad fónico-rítmica, que dota al poema de un poder sensorial que no deja lugar a la indiferencia, capaz, incluso, de inducir a una performatividad corporal en forma de pasos, saltos, gestos, palmadas, miradas o emisiones vocales diversas. Así, por ejemplo, es altamente probable que los cuatro versos finales del poema de José Manuel Espino sean acompañados como reacción espontánea a los estímulos textuales, por los movimientos algo convulsivos del «calambre» y sabrosamente sensuales de la caribeña «salsita». Algo similar — por lo demás tan común en el ámbito del juego- es bastante difícil de encontrar en la poesía contemporánea para adultos.

Aunque se ha hablado de significantes, está claro que ellos se manifiestan inextricablemente ligados a los significados, en una adecuación pragmática al destinatario no exenta de arduos conflictos entre las exigencias comunicativas y la cualificación estética; a veces felizmente resueltos, a veces en lamentable contradicción.

\section{IV}

Densidad isotópica por iteración de semas y por acumulación de efectos fónico-rítmicos contribuyentes a la comprensión y al disfrute textuales, no 
implica necesariamente univocidad semántica ni ausencia de la función estética, como demuestran tantos poemas logrados.

Entre aquel Escila pragmático y aquel Caribdis estético pasa la huidiza corriente de la auténtica poesía, conseguida, por ejemplo, en el siguiente poema de Mirta Aguirre (1912-1980):

\author{
Experiencia \\ Cucaracha Martínez viuda de Pérez, \\ se casará mañana con un alférez. \\ Cucaracha Martínez tapó la olla \\ y aseguró la tapa con una argolla. \\ Y cuando vaya a casa de su vecina, \\ cerrará bien la puerta de la cocina (1974: 50).
}

La relación hipertextual — según la ya evocada taxonomía de Gérard Genette - con el cuento popular latinoamericano de «La cucarachita Martina» es más que evidente y garantiza una sintonía inmediata con el lector potencial. Pero la autora, desde el título, anuncia que aprovechará solo una arista del hipertexto, que le permite prolongar la historia de una protagonista que aprendió bien las lecciones de los golpes de la vida. El matiz humorístico que aparta el poema de cualquier espíritu de moraleja, se acentúa mediante los cambios en el nombre del persona (un eco de las ridiculeces la crónica social parece resonar en ese eficacísimo primer verso), mediante las medidas muy realistas y muy prácticas, tan diferentes de la continuidad del cuento en que resucita Ratón Pérez ${ }^{5}$.

Tales hallazgos semánticos establecen una tupida red isotópica mediante componentes textuales como la iteración léxica del sujeto de las acciones y encuentran una apropiadísima correlación en los pareados dodecasílabos de rima consonante, que más que decir de modo terminante, en su austera brevedad multiplican la plurisignificación inherente a los textos literarios.

Por supuesto, esta es una lectura de adulto especializado y habrá siempre una zona de incertidumbre en torno a qué recepción específica hará del poema su destinatario niño, sea por iniciativa propia o con las mediaciones del adulto, expresión de la desfecha de que habló Mirta Aguirre en la «Introducción»a su libro Juegos y otros poemas. Mas tales virtualidades están sin dudas ahí, como estímulos a la semiosis y al goce artístico.

La vía de la solución al conflicto aludido entre comunicación y literariedad parece radicar en la aplicación más o menos intuitiva, o más o menos susten-

\footnotetext{
5 Véase «Cómo es que Ratón Pérez resucita y deja de llorar cucarachita», en Almendros [y Robés] (2011: pp. 68-74).
} 
tada en la información y la reflexión teóricas, de lo que Lev Vigotski (18961934) llamó Zona de Desarrollo Próximo, uno de los pilares de su concepción histórico-cultural acerca de la psiquis. En concreto: la mencionada adecuación textual al receptor supone al mismo tiempo un reto a la capacidad decodificadora de ese Lector Modelo, que impulse su ontogénesis hacia estadios superiores de socialización.

Bajo esta luz se explica, por mediocridad o por desfase informativo, la existencia de escritos infantilizantes y también tanto logro en que emerge una intertextualidad desarrolladora de nuevas adquisiciones culturales, un estímulo al dominio más cabal del lenguaje en sus dimensiones simbólicas, la incitación a una mayor sensibilidad ante lo estético. Un ejemplo ilustrativo de las razones precedentes, entre otros muchos posibles, es el texto siguiente, también de Mirta Aguirre, pleno de los non-dits, de los vacíos e intersticios, de todo lo subyacente que según Umberto Eco estimula poderosamente los movimientos cooperativos de parte del lector:

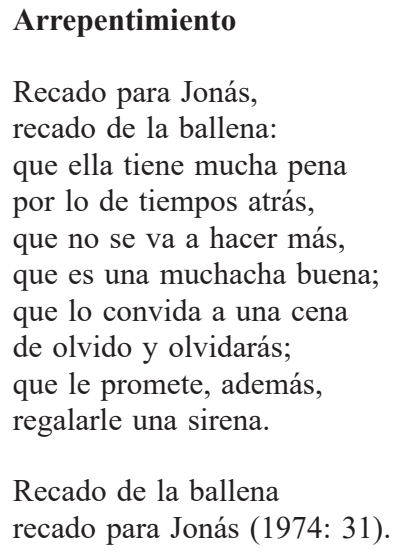

La adecuación pragmática al receptor, acompañada en las obras de calidad del estímulo al crecimiento personal de índole cognitiva y afectiva, moviliza, asimismo, en la poesía infantil, otros factores que tienden a conducir la recepción, pues como afirma Umberto Eco: «[...] prever su Lector Modelo no significa «esperar» a que exista, significa también actuar sobre el texto para desde él construirlo. Un texto reposa en una competencia, pero, además contribuye a producirla» $(1985: 50)^{6}$.

Todo lo anterior, que insiste en las frecuentes tensiones entre literariedad y comunicación en la poesía para niños, pone de relieve la eficaz contribución de los textos artísticamente logrados a la competencia literaria de ese lector

\footnotetext{
6 Traducción del autor.
} 
que, como reitera el citado teórico italiano, se potencia desde la escritura misma.

V

Resulta una singularidad de la lírica dedicada a la infancia la cercanía al género narrativo, detectable en marcas como:

- la abundante presencia de secuencias de acontecimientos organizados según una lógica tempo-espacial no tan desplegada como la del cuento, que es su paradigma, pero de notoria visibilidad;

— la inclusión de personajes portadores de dicha secuencia, caracterizados de modo somero, pero fácilmente distinguibles;

- la inclusión de diálogos explícitos entre los personajes, bastante infrecuentes en la poesía para adultos.

Todas estas marcas pudieran explicarse como el intento de dinamizar la comunicación, aprovechando el reconocido atractivo del cuento para el niño. Tales rasgos establecen una cierta ruptura con la naturaleza esencial de la lírica, centrada en el monólogo de su sujeto o hablante, tendiente a lo descriptivo y reflexivo, ubicada en un presente más bien intemporal o eterno. Esta ruptura puede haber contribuido a la subestimación de la poesía para niños, por incomprensión de esta particularidad suya, propensa más a revelar el exterior en movimiento que las interioridades de la conciencia, sin que ello excluya la posibilidad ocasional de la intensa concentración emotiva o el más frecuente despliegue de la descripción.

El empleo frecuentísimo de la personificación como figura retórica, particularmente aquella de carácter individualizante, con nombre propio incluido, es clara señal de la aludida narratividad, del deseo de otorgar dinamismo y corporeidad y, al mismo tiempo de seguir convenciones a veces muy erosionadas en su pretendida expresividad artística.

El siguiente poema de la excelente poeta argentina María Elena Walsh (1930-2011), entre muchos ejemplos posibles, ilustra cabalmente esa narratividad que permea la lírica destinada a la infancia:

\section{La vaca estudiosa}

Había una vez una vaca en la Quebrada de Humahuaca. Como era muy vieja, muy vieja, estaba sorda de una oreja. 
Y a pesar de que ya era abuela un día quiso ir a la escuela. Se puso unos zapatos rojos, guantes de tul y un par de anteojos.

La vio la maestra asustada y dijo: - Estás equivocada.

Y la vaca le respondió:

— ¿Por qué no puedo estudiar yo?

La vaca, vestida de blanco, se acomodó en el primer banco.

Los chicos tirábamos tiza

y nos moríamos de risa.

La gente se fue muy curiosa a ver a la vaca estudiosa.

La gente llegaba en camiones, en bicicleta y en aviones.

Y como el bochinche aumentaba en la escuela nadie estudiaba.

La vaca, de pie en su rincón rumiaba sola la lección.

Un día toditos los chicos se convirtieron en borricos.

Y en ese lugar de Humahuaca

la única sabia fue la vaca (Walsh, 2005: 23-24).

Este poema, repleto de hallazgos felices de toda índole, junto con su ejemplar fusión lírico-narrativa, pone de relieve otro rasgo de la poesía para niños que compensa la imposibilidad de las complejas introspecciones personales o las densas reflexiones filosóficas: la instauración de un desborde imaginativo, de filiación lúdico-fantástica, de resonancias a menudo humorísticas, que hacen florecer auténticos reinos de lo insólito y de lo sensorial, en grado tal que pudiera explicar por qué Thomas Stearns Eliot (1888-1965) además de escribir The Waste Land (1922) es también el autor de Old Possum 's of Practical Cats (1938); por qué tanto poeta de valoradísima obra para adultos se dedicó a crear para lectores que se iniciaban en la literatura. 
La dialéctica de tradición-innovación, que ha sido muchas veces a lo largo de la historia una lucha de muy enconados contrarios dispuestos a no ceder posiciones de poder en el campo literario, tiende en la LIJ toda, y quizás con mayor fuerza en la poesía, al polo de lo tradicional, de la continuidad: la métrica, el repertorio temático, el conjunto de medios retóricos así lo demuestran y la innovación, aun la más audaz — por tener en su horizonte al Lector Modelo niño - opera mediante rupturas parciales. La propia María Elena Walsh, que con Tutú Marambá, de 1960, y El reino del revés, de 1964, alcanzó el momento más radicalmente innovador de la lírica para la infancia escrita en español de todos los tiempos, no abandonó nunca la rima ni dio la espalda al caudal de la oralidad folclórica.

De esa aludida polarización se deriva un peligro vuelto realidad en innumerables textos: el desgaste semántico y lingüístico que posee su manifestación más visible en la lexicalización de palabras y sintagmas, que pueden llegar a ser tan banales e inexpresivos como «la pata de la mesa» o «la niña de los ojos». Hay en Cuba, por ejemplo, decenas de libros de versos para niños que presentan la palabra «sueño» en su título, con sentidos muy parecidos, como si ese vocablo fuera el mágico jábrete sésamo! de todo vuelo imaginativo y como si cada autor acabara de inventar la poesía, en una tábula rasa sin sombras del pasado.

Por suerte son también muchos los autores que aun sin protagonizar violentas rupturas le otorgan permanente nueva vida a esta creación lírica, pese a las constricciones del género, proyectadas sobre el escritor desde la diacronía y reveladas como naturaleza del Lector Modelo desde la sincronía.

VII

Así se manifiesta otro rasgo de la mejor poesía para niños: el predominio de la imagen sobre la abstracción, en específico de lo cromático, luminoso y dinámico, de notoria nitidez perceptual, imantadora de la atención, irradiadora de sentidos y coadyuvante al goce estético.

Un poema del español Carlos Murciano (1931), es representativo de esa sensorialidad visual e incluso táctil, acompañada en este caso de un cúmulo de felices aliteraciones:

\section{Lucila con $\mathbf{L}$.}

Lucila lame su helado.

El labio se le congela

y la lengua se le hiela 
con el hielo limonado.

$\mathrm{Su}$ abuelo mira alelado

como el barquillo vacío

destila un hilo de frío

que corta como un serrucho,

mientras en el cucurucho

se cuela el sol del estío (Pelegrín, 2003: 37).

En una cuerda más acendradamente lírica, el poeta venezolano Aquiles Nazoa (1920-1976) pone de manifiesto la riqueza de imágenes de la poesía para niños en «Método práctico para aprender a leer en VII lecciones musicales con acompañamiento de gotas de agua», del que se transcribe un fragmento:

\section{Lección II}

$$
\begin{aligned}
& \text { Papá } \\
& \text { p-a-p-á } \\
& \text { pa-pá }
\end{aligned}
$$

Mi papá era Simbad el Marino.

Mi papá tiene un barco de vela y un tren. Y un caballo blanco

de general. Y un cinturón de hebilla de plata.

Mi papá es cazador y el tuyo no.

Mi papá me trajo del bosque una mariposa verdeazulmar y un arcoíris chiquito que encontró desnudo en el fondo del río.

La voz de mi papá es como el viento entre los pinos (2010: 133-134).

\section{VIII}

La depurada voz de niño del poema de Nazoa conduce las presentes reflexiones hacia un terreno pródigo en peculiaridades interesantes: el de la enunciación lírica del poema.

El sujeto o hablante lírico, entidad enunciadora que como se sabe, se constituye en la totalidad del texto mismo, presenta en la poesía infantil aristas derivadas de una situación comunicativa especial, pues:

— existe una inevitable distancia psicológica y sociocultural entre el emisor adulto y el receptor niño;

- es muy frecuente la adopción de una voz indeterminada, neutra, que no se implica en el mensaje, como si se borrara el yo enunciador, esencial en la lírica; 
- la constitución de un sujeto lírico niño presenta el riesgo del aniñamiento y de otras inautenticidades derivadas de los aspectos enumerados.

En relación con lo anterior llama la atención la escasez de determinados hablantes líricos niños que enuncien mensajes poéticos acerca de asuntos que interesan intensamente a la niñez como el deporte (apenas existen, por ejemplo poemas para niños sobre béisbol o fútbol en América Latina, donde ambos son pasión diaria de los varones e incluso de muchas niñas), o sobre el enamoramiento temprano, y se reitera aquello que le parece al emisor adulto digno de comunicación, porque en sus recuerdos de hace veinte, treinta o cuarenta años, fue algo inolvidable. De tales desajustes, por no hablar de autoritarismos didactizantes que hacen trizas cualquier diálogo verdadero, surgen en la poesía infantil tantos desequilibrios y barreras entre hablante y receptor.

La impersonalidad o ajenidad del sujeto lírico en numerosa poesía para niños pudiera asociarse a la frecuente fusión en ella de rasgos líricos y épicos referida en un momento anterior de estos apuntes. Ese sincretismo lírico-épico, que alcanza en la fábula en verso su forma canónica, parece acercar el discurso a las convenciones narrativas y provoca la emergencia de un cuasi-narrador que cuenta, describe y eventualmente otorga voz a esbozos de personajes, en alejamiento del monólogo expresivo de la subjetividad personal, central de la poesía.

Parece, asimismo, ser un indicio muy revelador del talento en la escritura de poesía para niños el aunar sin fisuras narratividad y lirismo, de modo que se ofrezcan imágenes dinámicas vinculadas con seres de gran pregnancia sensorial y a la vez, directa o indirectamente se hable de sí mismo y se creen atmósferas evocadoras y sugerentes, de notable intensidad tonal. Si bien todos los ejemplos transcritos en pos de demostrar las ideas expuestas pudieran apoyar ese último aserto, el poema que sigue de Federico García Lorca (18981936) es un paradigma de tal fusión armoniosa:

\section{EI lagarto está llorando}

El lagarto está llorando.

La lagarta está llorando.

El lagarto y la lagarta con delantalitos blancos.

Han perdió sin querer su anillo de desposados. ¡Ay, su anillito de plomo, ay, su anillito plomado!

Un cielo grande y sin gente monta en su globo a los pájaros. 
El sol, capitán redondo,

lleva un chaleco de raso.

¡Miradlos que viejos son!

¡Qué viejos son los lagartos!

¡Ay como lloran y lloran,

ay, ay, cómo están llorando! (Pelegrín, 2003: 79).

La cercanía a la inteligencia y la sensibilidad de la infancia puede seguir mil caminos poéticos y todos son válidos. Tres de ellos suelen estar entre los más recorridos: el de la invención del sujeto lírico niño; el de un yo reconocido como adulto, pero que hace suya una visión trasuntada en el lenguaje, orgánicamente infantil del mundo; el de un hablante adulto que desde esa adultez se dirige al niño en un intento de intercambio de tú a tú, pese a las diferencias de uno y otro.

Del primer caso son representativos los poemas transcritos de Aquiles Nazoa y María Elena Walsh, del segundo un texto como el siguiente de Nicolás Guillén (1902-1989):

\author{
¿Quién? \\ ¿Quién quiere aceituna, \\ quién quiere melón \\ cañutos de caña, \\ sopa de pichón? \\ — ¡Yo, yo, yo! \\ Pues que baile un son. \\ ¿Quieres tú la estrella \\ que anoche encendí, \\ y una mariposa \\ de hierro y marfil? \\ — ¡Sí, sí, sí! \\ Pues que baile aquí. \\ Muela de cangrejo, \\ verde platanal, \\ heridas de amor \\ nunca sanarán (1978: 28).
}

Y del tercero, un poema de Gloria Fuertes, de humanísima visión lírica del mundo, teñida de humor sutil, que intuye en el pequeño lector un ser a la altura de la complejidad del texto: 


\section{Los pájaros no tienen dientes}

Los pájaros no tienen dientes, con el pico se apañan.

Los pájaros pescan peces

sin red ni caña.

Los pájaros, como los ángeles, tienen alas.

Los pájaros son artistas

cuando cantan.

Los pájaros colorean el aire

por la mañana.

Por la noche

son músicos dormidos

en las ramas.

Da pena ver a un pájaro en la jaula ${ }^{7}$.

IX

Se ha tratado de demostrar, sin pretensiones de exhaustividad, lo viable de un estudio teórico de la poesía infantil, de base pragmática, pero signado por la pluralidad, dado el carácter complejo de este objeto de análisis, tan merecedor como cualquier otro de acercamientos acordes con el desarrollo de las ciencias de la literatura y del lenguaje.

La poesía infantil postula un Lector Modelo en proceso de conformar su competencia literaria, de atención inestable, ávido del juego y cuyo pensamiento asciende gradualmente desde lo imaginal a lo abstracto.

Tal conocimiento de la ontogénesis del niño — por la vía intuitiva o mediante el auxilio de la ciencia- determina una adecuación pragmática que no es en los textos artísticamente logrados mera adaptación, sino impulso a la socialización y al crecimiento espiritual de la infancia, es decir, fuente de satisfacción de necesidades actuales y motivación para la aparición de necesidades futuras de más amplia dimensión humana.

La vuelta del lenguaje hacia sí mismo en una materialidad fónico-rítmica de los significantes estimuladora de acciones lúdicas; la intertextualidad con el caudal folclórico oral; la densidad isotópica favorecedora de la coherencia textual; la narratividad dinamizadora del discurso; el predominio de lo imaginal sobre lo abstracto; la constitución frecuente de hablantes líricos infantiles, son, entre otros, factores que tienden a estimular la recepción y que caracterizan a un género literario proclive a una relación singular con la tradición y que se

\footnotetext{
7 Recogido en: <http://www.juntadeandalucia.es/averroes/centros-tic/14000744/helvia/ sitio/upload/PoemasGloriaFuertes.pdf> [ref. de 19/07/2017].
} 
mueve entre tensiones resueltas ejemplarmente en la obra de muchos poetas de alta maestría creadora.

Puede que la poesía sea siempre uno de los grandes misterios del cosmos al que le canta. Desentrañar ese enigma mayor es una inclinación tan atávica como reverenciarlo en su insondable belleza. Una lectura reveladora de componentes e interacciones de su naturaleza profunda es tan válida y necesaria como la fascinación ante sus dones, pues, desde la nana que adormece al recién nacido, hasta el difícil poema torrencial para lectores maduros, la poesía es y será siempre testimonio ineludible de lo más esencial de la condición humana.

\section{BIBLIOGRAFÍA CITADA}

Aguirre, Mirta (1974). Juegos y otros poemas. La Habana: Gente Nueva.

Almendros, Herminio [y Ruth Robés Masses] (2011). Había una vez. La Habana: Gente Nueva. Edición príncipe de 1946.

Alonso, Dora (1989). Palomar. La Habana: Gente Nueva.

Cerrillo, Pedro César y Ángel Luis Luján (2010). Poesía y educación poética. Cuenca: Universidad de Castilla-La Mancha.

Cerrillo Torremocha, Pedro César y César Sánchez Ortiz (coord.) (2010). Tradición y modernidad de la literatura oral [Homenaje a Ana Pelegrín]. Cuenca: Universidad de Castilla-La Mancha.

Chacón y Calvo, José María (1989). «Lo popular hispánico en "Los dos príncipes"», en Salvador Arias (selección y pról.), Acerca de La Edad de Oro. La Habana: Centro de Estudios Martianos/Editorial Letras Cubanas, pp. 172-180.

Dubois, Jacques (1988). «Del modelo institucional a la explicación de los textos», Criterios. Teoría literaria, estética, culturología. 31-24, pp. 46-52.

Eco, Umberto (1985). Lector in fabula. Le rôle du lecteur. Paris: Grasset \& Fasquelle.

Espino, José Manuel (2003). El libro de Nunca-Jamás. La Habana: Gente Nueva.

Florit, Eugenio (1989). «Los versos de La Edad de Oro», en Salvador Arias (selección y pról.), Acerca de La Edad de Oro. La Habana: Centro de Estudios Martianos/Editorial Letras Cubanas, pp. 51-53.

García Montero, Luis (1989). Lecciones de poesía para niños inquietos. Granada: Comares. Greimas, Algirdas Julien (1970). Du sens. Essais sémiotiques. Paris: Seuil.

Guillén, Nicolás (1978). Por el Mar de las Antillas anda un barco de papel. La Habana: Unión.

Hazard, Paul (1989). Los libros, los niños y los hombres. La Habana: Gente Nueva.

Jakobson, Roman (1974). Estilo del lenguaje. Madrid: Cátedra.

Lerer, Seth (2009). La magia de los libros infantiles. De las fábulas de Esopo a las aventuras de Harry Potter. Barcelona: Crítica.

López Tamés, Román (1990). Introducción a la literatura infantil. Murcia: Universidad de Murcia.

Marinello, Juan (1989). «Los versos de La Edad de Oro: tradición y novedad», en Salvador Arias (selección y pról.), Acerca de La Edad de Oro. La Habana: Centro de Estudios Martianos/Editorial Letras Cubanas, pp. 181-184.

Martí, José (2005). La Edad de Oro. La Habana: Centro de Estudios Martianos. 
Meek, Margaret (2001). «¿Qué se considera evidencia en las teorías sobre literatura para niños?», en Un encuentro con la crítica y los libros para niños. Caracas: Banco del Libro, pp. 15-30.

Nazoa, Aquiles (2010). Sencillamente Aquiles. Caracas: Monte Ávila Editores Latinoamericana.

Navarro, Desiderio (selección y trad.) (1997). Intertextualité. Francia en el origen de un término y el desarrollo de un concepto. La Habana: UNEAC/Casa de las Américas/ Embajada de Francia en Cuba.

Nobile, Angelo (1992). Literatura infantil y juvenil: la infancia y sus libros en la civilización tecnológica. Madrid: Morata.

Pelegrín, Ana (selección y pról.) (2003). Poesía española para niños. Madrid: Alfaguara.

Portuondo, José Antonio (1989). «Análisis de la obra poética «Los dos príncipes»», en Salvador Arias (selección y pról.), Acerca de La Edad de Oro. La Habana: Centro de Estudios Martianos/Editorial Letras Cubanas, pp. 157-171

Prado, Benjamín (2000). Siete maneras de decir manzana. Madrid: Anaya.

Riffaterre, Michael (1971). Essais de stylistique structurale. Paris: Flammarion.

Shavit, Zohar (2009). Poetics of Children's Literature. Athens: University of Georgia Press.

Soriano, Marc (2005). La literatura para niños y jóvenes. Guía de exploración de sus grandes temas. Graciela Montes (trad., adaptación y notas). Buenos Aires: Colihue.

Walsh, María Elena (2005). Tutú Marambá. Buenos Aires: Alfaguara. Biblioteca María Elena Walsh.

Fecha de recepción: 24 de marzo de 2015.

Fecha de aceptación: 1 de octubre de 2015. 